\title{
A dignidade das pertenças e os limites do neoliberalismo: catástrofes, capitalismo, Estado e vítimas
}

JOSÉ MANUEL MENDES"

\section{Resumo}

Neste artigo aborda-se a forma como as catástrofes revelam a lógica de funcionamento e de atuação do capitalismo, e como, no limite, os Estados são o garante último de apoio e de reconstituição dos laços sociais e das comunidades, após a ocorrência de um desastre. Argumenta-se que o Estado é o mediador e o recurso de última instância legitimador da integração das sociedades no capitalismo global, e que a linha abissal que define os integrados e os descartáveis ou invisíveis percorre tanto o Sul como as pequenas colónias do Norte, tanto as lógicas de regulação/ emancipação como as de apropriação/violência que existem tanto no Norte como no Sul globais. O artigo está estruturado em três partes. Numa primeira, procede-se a uma discussão sobre as novas formas que assumem o capitalismo avançado e o neoliberalismo. Numa segunda parte, discute-se criticamente a noção de risco, e como as catástrofes podem ser reveladoras da lógica do capitalismo e dos limites do neoliberalismo. A terceira parte centra-se no papel das vítimas e dos afetados, e na forma como estes exigem uma análise baseada na performatividade, para além da biopolítica de Michel Foucault ou dos regimes de exceção de Giorgio Agamben. ${ }^{1}$

Palavras-chave: Catástrofe. Estado. Capitalismo e neoliberalismo. Vítimas. Performatividade.

\footnotetext{
Centro de Estudos Sociais (CES) da Universidade de Coimbra (Portugal)

${ }^{1}$ Este artigo foi elaborado no âmbito do projeto de investigação "ALICE - Espelhos Estranhos, Lições Imprevistas: Definindo para a Europa um novo modo de partilhar as experiências do Mundo", coordenado por Boaventura de Sousa Santos (alice.ces.uc.pt) no Centro de Estudos Sociais da Universidade de Coimbra - Portugal. O projeto é financiado pelo Conselho Europeu para a Investigação, 7o Programa Quadro da União Europeia (FP/2007-2013) /ERC Grant Agreement n. [269807]".
} 


\section{The dignity of belonging and the limits of neoliberalism: disasters, capitalism, State and victims}

\section{Abstract}

This article discusses how catastrophes reveal the logics underlying capitalism's operation and how, at the limit, States are the last guarantor for support and reestablishment of social bonds and of communities, following a disaster. It is argued that the State is the mediator and the last resort, which legitimizes the integration of societies in global capitalism, and that the abyssal line, which defines who is included and who is disposable, runs through both South and the small colonies of the North, through both the logics of regulation/emancipation and of appropriation/violence that exist in the Global North as in the Global South. The article is structured in three sections. First, it discusses the new forms taken by advanced capitalism and neoliberalism. The second part discusses critically the concept of risk and how catastrophes can reveal capitalism logic and the limits of neoliberalism. The third section focuses on the role of victims and the affected people and on the way they demand an analysis based on performativity, and beyond Michel Foucault's biopolitics and Giorgio Agamben's exception regimes.

Keywords: Catastrophe. State. Capitalism and neoliberalism. Victims. Performativity.

\section{Introdução}

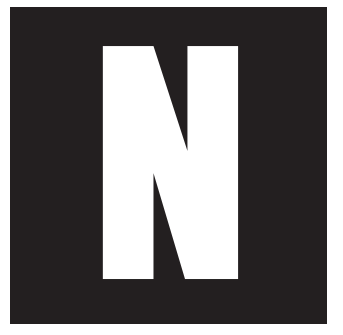

este artigo, procuro responder à seguinte questão: o que dizem as catástrofes sobre o capitalismo e o Estado? Mas, mais importante, procuro apreender o que revelam as vítimas e os afetados sobre o capitalismo e o Estado. Porque os afetados e as vítimas produzem lugares, tempos e espaços de indeterminação e, na sua materialidade, possibilitam uma recusa e o abandono da representação, e, como sugerem Patricia Clough Smith e Craig Willse, 
[...] abandonar a representação, não só devido à não representabilidade mas sim à mudança ontológica da performance na construção do significado para a performance com o objetivo da modulação afetiva dos corpos e das populações. Nesta mudança, o excesso é substituído pela indeterminação, abrindo a crítica a uma abordagem não-fenomenológica (Smith; Willse, 2011, p. 12)².

Neste artigo, procuro discutir as lógicas do capitalismo, tendo como ponto de entrada os acontecimentos extremos e, mais especificamente, os desastres ou catástrofes. O que nos dizem os mesmos sobre o modo como o capitalismo e a sua versão avançada na forma do neoliberalismo constituem as suas práticas de reprodução e as suas formas ideológicas de legitimação?

Os acontecimentos extremos, quer no Norte quer no Sul globais, tendem a aumentar a legitimação da intervenção do Estado, muitas das vezes com a suspensão das normas sociais e económicas, criando um estado de exceção, que indicia a presença inelutável desse mesmo Estado. Estes acontecimentos extremos colocam desafios concretos na produção de conhecimentos nas ciências sociais e naturais que, na maioria dos casos, coarctam a suposta autonomia das ciências.

Argumento, neste artigo, que o Estado é o mediador e o recurso de última instância, legitimador da integração das sociedades no capitalismo global, e que a linha abissal que define os integrados e os descartáveis ou invisíveis (Santos, 2007) percorre tanto o Sul como as pequenas colónias do Norte, tanto as lógicas de regulação/emancipação como as de apropriação/violência que existem tanto no Norte como no Sul globais.

Os conceitos e as formas políticas tradicionais, como Estado, cidadania, soberano, soberania, povo, não são operantes em situações de catástrofe. E as vítimas e os afetados entram para indicar, para indiciar,

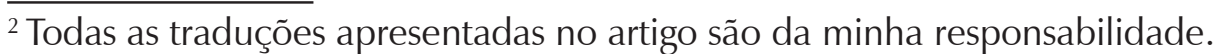


como detectores naturais, a ficção política e a arbitrariedade dos supostos laços sociais e políticos primordiais.

A vítima, em si, não é produtora de cidadania; é, sim, interpeladora da ficção da comunidade imaginada. A vítima pode ser transportadora de uma nova relação entre o Estado e as pessoas. Se organizada em comunidades, em associações ou em movimentos sociais, pode ser veiculadora de uma ação coletiva que desnuda, que revela e denuncia os pressupostos do capitalismo e do neoliberalismo.

As vítimas desserializam a população. Não se pode fazer biopolítica e governamentalidade com as vítimas. E é na sua diferença, na sua indeterminação, nos corpos em sofrimento ou sem vida, que, muitas vezes, podem ser convertidas em estratégias de reivindicação de cidadania, que colocam a nu a arbitrariedade da relação cidadãos/Estado.

Este artigo está estruturado em três partes. Numa primeira, procedo a uma discussão sobre as novas formas que assumem o capitalismo avançado e o neoliberalismo. Contudo, argumentarei que o Estado mantém a sua importância e, mais do que tudo, é essencial para a plena consecução das políticas neoliberais.

Na segunda parte discuto criticamente a noção de risco, e como os desastres e as catástrofes podem ser reveladores da lógica do capitalismo e dos limites do neoliberalismo.

$\mathrm{Na}$ terceira parte, centro-me no papel das vítimas e dos afetados, e na forma como estes exigem uma análise que vá para além da biopolítica de Michel Foucault ou dos regimes de exceção de Giorgio Agamben. 


\section{Neoliberalismo e o Estado: as muitas faces do capitalismo}

As questões sobre a história, a configuração e o futuro do capitalismo continuam a desafiar os intelectuais e os cientistas sociais no Ocidente (Derlugian, 2013). Temos contributos de grande valor e perspicácia para se entender a história global do capitalismo como sistema económico e como força de acumulação e de distribuição do capital (Arrighi, 2010). A busca de alternativas ao capitalismo também tem estimulado algumas reflexões interessantes, entre as quais a de Erik Olin Wright (2010) sobre a possibilidade de utopias reais.

Mas, há que olhar de forma crítica a questão da homoeficiência do capitalismo, isto é, da sua capacidade como sistema para fazer o mesmo ou ter o mesmo efeito, independentemente das variações das condições locais (Mitchell, 2011, p. 203, nota 25). Dito de outro modo, há que atender ao que Dipesh Chakrabarty chama de pecados do historicismo, isto é, a ideia de que para se compreender algo o mesmo tem que ser visto como um todo e no seu desenvolvimento histórico (Chakrabarty, 2008, p. 6).

No seu brilhante livro sobre o colonialismo e o Egito, Timothy Mitchell propõe que se escreva sobre o capitalismo sem lhe atribuir uma lógica interna ou uma coerência - que o mesmo não tem -, de forma a evitar a reprodução da sua inelutabilidade (Mitchell, 2002, p. 14). Ou seja, todos os fatores que costumam ser analisados, como os factos políticos, as instituições, as dinâmicas sociais, os processos culturais, tendem a subsumir-se sempre à história e à lógica do capitalismo, que emerge como algo de essencial, de autocontido. Todos os outros fatores invocados pelos investigadores são descritos de forma negativa e fora do princípio do mercado (Mitchell, 2002, p. 245-246).

Para Timothy Mitchell, o capitalismo não tem uma lógica ou uma essência, transforma-se, conforme as forças e os obstáculos que vai encontrando. O capitalismo é, assim, indeterminado. $\mathrm{O}$ autor mostra isto de 
forma magistral no seu livro sobre a democracia do carvão, que trata da história do petróleo e do seu impacto no capitalismo e nos diferentes regimes políticos. Para apreender a especificidade do que estudou, e da forma como o capitalismo se metamorfoseou na transição do carvão para o petróleo, Mitchell criou o termo McJihad, em diálogo com o famoso livro de Benjamin Barber (1996). Para Mitchell, o termo Mcjihad não deriva de uma contradição entre a lógica do capitalismo e as outras forças ou ideias que este encontra; antes, remete para a ausência de qualquer lógica inerente ao capitalismo (Mitchell, 2011, p. 232). Seguindo as propostas de Mitchell, há que atender às configurações que o capitalismo assume nos contextos específicos onde opera, e à sua relação complexa com as formas de Estado, as culturas e as sociedades que encontra.

$\mathrm{Na}$ versão de capitalismo dominante que emergiu a partir dos anos 1970, o neoliberalismo, as melhores análises têm sido propostas por autores que se situam nos estudos da governamentalidade, na esteira de Michel Foucault. Nesta perspectiva, segundo Nikolas Rose, há que analisar as tecnologias de governo ativadas concretamente pelo neoliberalismo, como um agenciamento (assemblage $)^{3}$ de estratégias, forças, procedimentos, técnicas e dispositivos (Rose, 1996, p. 42).

Para Nikolas Rose, o neoliberalismo apresenta as seguintes características: uma nova relação entre peritos e política, que se baseia em ciências cinzentas, que fomentam regimes de cálculo e de gestão financeira, tornando as instituições, organizações e pessoas mensuráveis e auditáveis; uma nova pluralização e autonomização das tecnologias sociais, com a desgovernamentalização do Estado e a desestatização do governo, que

\footnotetext{
${ }^{3} \mathrm{O}$ conceito de agenciamento é a tradução portuguesa de agencement, introduzido por Gilles Deleuze e Félix Guattari no seu livro Mil Planaltos (2008). A tradução em inglês para assemblage não dá a ideia correta do termo original, assim como a tradução portuguesa. Optei por manter a tradução portuguesa da edição da obra de Deleuze e Guattari, já de uso generalizado pelos académicos portugueses.
} 
implicam uma nova noção do social, em que se passa do cidadão social para o cidadão responsável inserido numa comunidade autogovernada; e, por último, uma nova especificação do sujeito de governo, definido como um cliente, como empresário de si, com completa racionalização das escolhas feitas e a fazer (Rose,1996, p. 55-57).

Mas, como bem refere Aihwa Ong na sua crítica às teses universalizantes de Michael Hardt e de Toni Negri sobre a confrontação do capital global com as multitudes desenraizadas, não se pode confundir e fundir soberania política e poder capitalista, pois estas são duas tecnologias de poder separadas e que interagem de forma complexa (Ong, 2012, p. 26). ${ }^{4} \mathrm{~A}$ noção do neoliberalismo como uma tecnologia de governo desafia a visão convencional do capitalismo como destruidor da soberania política, ou do neoliberalismo como um conjunto irredutível de elementos que caracterizam nações inteiras. Nas suas palavras, e para o caso chinês:

O exercício flexível da exceção - por exemplo, a favor do capital quando a economia está em crescimento, mas a favor do trabalho quando as coisas se descontrolam - mantém os trabalhadores atados e disciplinados pelo projeto nacionalista da economia chinesa, dando-lhe também meios para reinar no mundo corporativo (Ong, 2012, p. 28).

A complexidade da interação entre Estado e regime económico, entre Estado e capitalismo, obriga à análise separada dessas duas formas de poder. ${ }^{5}$ Como refere Philip Mirowski, o construtivismo está na base da narrativa do neoliberalismo (Mirowski, 2013, p. 53). Se, para o neolibe-

\footnotetext{
${ }^{4}$ Aihawa Ong demonstra isso de forma clara na sua obra magistral Neoliberalism as exception (2009), na qual descreve os espaços e as políticas que, na Ásia, podem ser vistos como exceções ao neoliberalismo, implicando lógicas e processos tanto de inclusão como de exclusão, que desestabilizam as práticas estabelecidas de cidadania e de soberania.

${ }^{5}$ Béatrice Hibou (2012) mostra de forma convincente como a agenda neoliberal se implementa pela burocratização crescente da vida profissional e quotidiana das pessoas. É, assim, pela lei e pela burocracia, que se estruturam os processos políticos de desconstrução do Estado-providência e dos direitos sociais.
} 
ralismo, a solução dos problemas das pessoas e as políticas públicas não passam pelo conceito de sociedade, esse mesmo neoliberalismo assenta numa lógica de autoridade, onde o Estado deve ser forte para produzir e garantir uma sociedade de mercado estável (Mirowski, 2013, p. 54).

Isto até porque o Estado, recuperando aqui as propostas de Boaventura de Sousa Santos $(1995,1994)$, assenta numa heterogeneidade interna dos espaços estruturais, que os torna dependentes uns dos outros para a sua reprodução e conduz a relações instáveis entre os mesmos, originando lógicas de atuação heterogéneas e fragmentadas. O Estado emerge como incompleto e contraditório nas suas práticas e políticas, atuando de forma oscilante e imprevisível entre um Estado predador e um Estado protetor.

Como refere Akhil Gupta, devem-se analisar os processos associados ao Estado, e não operar com a categoria reificada de Estado. Gupta opta por falar no Estado na Índia, e não sobre o Estado indiano, como categoria analítica única (Gupta, 2012 p. 13-14). Para Gupta, não se pode compreender a violência estrutural associada à pobreza extrema e à indiferença do Estado na Índia, sem primeiro compreender o que significa o Estado para diferentes indivíduos, grupos, organizações e comunidades (Gupta, 2013, p. 688).

Gupta coloca uma pergunta essencial para todos os que estudam o Estado e, no nosso caso, para a análise da relação entre o Estado, as catástrofes e o capitalismo: em quais condições, o Estado emerge como unitário? (Gupta, 2013, p. 689). Disso derivam as limitações das teorias institucionais sobre o Estado, dado que estas não atendem ao significado e à representação associados ao termo Estado em diferentes contextos. 
2. Risco, precaução e as catástrofes como reveladoras da lógica do capitalismo

Os acontecimentos extremos, como desastres e catástrofes, mostram o trabalho político para colocar os grupos e os indivíduos descartáveis fora das redes sociais e das comunidades nacionais imaginadas (Mendes, 2010). As ciências sociais, como tecnologias humildes (Jasanoff, 2005, 2003), devem tornar visíveis as pessoas e os grupos situados nos interstícios dos alinhamentos sociotécnicos e participarem do trabalho coletivo necessário para relatar e personificar essas pessoas e esses grupos num processo político de cidadania plena.

$\mathrm{Na}$ discussão do tema dos desastres, a catástrofe como imagem que tudo coloca em causa não está tão presente. A catástrofe é o oposto da questão social e da lógica subjacente ao Estado social. Segundo François Ewald (1986), o risco é uma tecnologia central do estado-providência, e os seguros, sobretudo associados aos acidentes de trabalho, foram a forma que a sociedade adoptou para a proteção em relação aos riscos que o seu próprio desenvolvimento originou.

Posteriormente, Ewald, após afirmar que as sociedades ocidentais se tinham baseado no paradigma da responsabilidade, no século XIX, e no paradigma da solidariedade, no século XX, anuncia uma nova mudança de paradigma e uma crise que se avizinha. Este novo paradigma assenta no princípio da precaução (Callon; Lascoumes; Barthe, 2001). O princípio de precaução associa-se diretamente à ideia de que os riscos são produzidos, agora, pela ação humana (Beck, 2008; 1992; Ewald, 2002, p. 282- 283).

Mas, na nossa perspectiva, qualquer neoliberalismo fracassa perante a catástrofe. As catástrofes problematizam o capitalismo em si e o próprio Estado. A catástrofe decompõe o Estado e o capitalismo e a suas articu- 
lações complexas. Como vimos anteriormente, a presença de um Estado forte constitui um dos pressupostos basilares do neoliberalismo (Mirowski, 2013). Mas, as situações de catástrofe obrigam à intervenção do Estado nas questões sociais, para além das questões securitárias ou de regulação dos mercados, de forma a repor a normalidade, os laços sociais, apoiando as comunidades e fomentando a ação coletiva. Mesmo se, como argumenta Naomi Klein (2007), posteriormente, o neoliberalismo torne a catástrofe uma oportunidade de negócio. ${ }^{6}$

Assim, as situações extremas revelam como funcionam as instituições. As situações extremas devem ser analisadas como indiciadoras de um tipo de Estado, de um tipo de contrato social e de uma sociedade civil, e da capacidade de mobilização das pessoas, dos grupos sociais e das comunidades.

Como exemplos que revelam a forma como os Estados veem os seus cidadãos e, de forma mais geral, os afetados por catástrofes, pode-se apontar os seguintes: o não aviso das populações costeiras do Chile da chegada do tsunami pela Marinha chilena, no terramoto de 27 de Fevereiro de 2010 (cerca de 500 mortos); a atuação das autoridades norte-americanas em Nova Orleães, após o furacão Katrina, em 2005, e com a presença ainda hoje de mais de 100.00 deslocados; o não aviso pelo governo japonês da dispersão da radioatividade, após um tsunami ter atingindo Fukushima em 11 de Março de 2011, ocultando os mapas fornecidos pelos Estados Unidos, ou, o aumento administrativo, pelo mesmo governo, da radiação permitida para o ser humano de 1,2 para 20 milisieverts/ano, na zona de influência de Fukushima; os milhares de idosos

\footnotetext{
${ }^{6}$ Por exemplo, as obrigações de catástrofe (cat bonds) transferem um conjunto de riscos de um patrocinador, normalmente o Estado, para os investidores. Este tipo de obrigações apareceu no mercado financeiro em meados dos anos 90, depois do furacão Andrew e do terramoto de Northridge que atingiram os Estados Unidos (von Dahlen; von Peter, 2012). Vários autores propuseram análises críticas da lógica dos seguros e do desenvolvimento de mecanismos de cálculo ligados ao risco e à catástrofe (Bougen, 2003; Collier, 2008; Power, 2007).
} 
que morreram em Paris, na onda de calor de 2003; os 50.000 cidadãos e cidadãs russas que morreram na onda de calor de 2010; os mineiros do urânio no Níger ou na Urgeiriça (Portugal) ou em Limoges (França) que não contam como parte da nuclearidade; ou, o apelo ao sacrifício, em nome da construção da nação da Índia, das comunidades que vivem junto de lugares contaminados com tório.

Como bem refere Steve Kroll-Smith, os conceitos universais, como cidadania, Estado e globalização, só podem ser entendidos na teia concreta das suas articulações num tempo e num espaço. E, para este autor, no seu estudo comparativo sobre o incêndio de São Francisco, de 1906, e o furacão Katrina em Nova Orleães, em 2005:

[Estas] verdadeiras catástrofes totais, arrancaram à epiderme destas sociedades urbanas o verniz da ordem e do civismo, expondo a crua e frequentemente primitiva máquina do poder político e classista que, em períodos normais, funciona logo abaixo da superfície (Kroll-Smith, 2012, p. 275).

O meu argumento é de que as catástrofes revelam a interiorização da linha abissal no centro do capitalismo, isto é, uma terceiro-mundialização do centro do sistema-mundo. Em situações extremas, as linhas abissais, às quais se refere Boaventura de Sousa Santos, tornam-se mais vincadas, entre o Norte e o Sul, mas também dentro de cada Estado (Santos, 2007). Boaventura de Sousa Santos argumenta, assim, que a tensão entre regulação e emancipação coexiste com a tensão entre apropriação e violência, esta última característica dos espaços colonizados (Santos, 2007, p. 11).

Assiste-se, com a proliferação de catástrofes em nível internacional, a uma nacionalização das linhas abissais. O acentuar da linha abissal dentro de cada país, coloca cada vez mais pessoas, na acepção de Boaventura de Sousa Santos, na sociedade civil incivil, sem direitos e sujeita a fascismos sociais (Santos, 2003, p. 24-25). 
Jean-Luc Nancy, refletindo sobre o impacto nacional e mundial da catástrofe de Fukushima, afirma que este equivalente geral que a catástrofe revela é o domínio do dinheiro, recuperando a formulação original de Marx. Para Nancy, já não há catástrofes naturais, e ao que assistimos é a uma catástrofe civilizacional que se propaga sempre que há um desastre. Nas suas palavras, tudo é absorvido no equivalente económico:

Esta absorção passa por uma estreita conexão entre o capitalismo e o desenvolvimento técnico tal como o conhecemos. É a conexão, precisamente, de uma equivalência e de uma intermutabilidade ilimitada das forças, dos produtos, dos agentes ou atores, dos significados ou valores - pois o valor de todo o valor é a equivalência (Nancy, 2012, p. 16).

Jean-Luc Nancy apresenta, de forma lapidar, esta relação umbilical entre a coisa económica e o capitalismo, no seu princípio desenfreado de tornar tudo equivalente e mercadorizável. Não é um capitalismo de desastre, como propõe Naomi Klein (2007), é a lógica do próprio capitalismo, desde sempre associado à exploração colonial e neocolonial. ${ }^{7}$

Boaventura de Sousa Santos (2009), por seu lado, propõe uma tipologia com cinco discursos de produção de uma alteridade radical nos espaços coloniais, com lógicas específicas de intervenção dos espaços da metrópole e do Norte global e com dinâmicas próprias de globalização: a tropicalidade; o desenvolvimento; os desastres; a produção de drogas ilegais e, por último, o terrorismo.

A geografia histórica dos desastres mostra à evidência as estratégias hegemónicas e performativas de produção de um mundo inseguro. Como bem o mostrou Greg Bankoff (2007; 2004), o topos dos desastres natu-

\footnotetext{
${ }^{7}$ Para uma análise pungente do colonialismo na fase posterior às independências, ver Kwame Nkrumah (1965), que cunhou o termo neocolonialismo. O caso mais paradigmático de uma catástrofe de perfil totalmente neocolonial é o da explosão da fábrica da Union Carbide em Bhopal, em 1984. Para um estudo exemplar sobre as causas e as consequências do acidente, e os fortes impactos sociais do mesmo, ver Jasanoff (1994).
} 
rais substituiu, no final do séc. XX, os topoi da tropicalidade (a condição de doença é resolvida pela medicina ocidental) e do desenvolvimento (a condição da pobreza é resolvida pelo investimento e pela ajuda ocidentais) na produção de um outro exótico, perigoso e distante.

Este artigo centra-se, sobretudo, no topos dos desastres. De uma primeira abordagem clássica, baseada no risco e nos peritos, passou-se, com a criação pelas Nações Unidas da Década Internacional para a Redução dos Desastres, para o discurso sobre resiliência e o papel das comunidades. Esta atenção política à redução da vulnerabilidade e ao incremento da resiliência, instigadora de inúmeras investigações e propostas de análise teóricas e empíricas, tem centrado o debate mais na redução dos custos e na mensuração técnica e operacional da vulnerabilidade, do que nas questões de cidadania, qualidade de vida e segurança estrutural das populações. A própria transição de um paradigma da vulnerabilidade para um paradigma assente na resiliência obriga a perguntar se o discurso subjacente não implica, na verdade, uma transferência de responsabilidades das entidades internacionais e governamentais para as comunidades e os cidadãos. A meu ver, o discurso da resiliência recai sobre as populações com fracos recursos para tornarem os riscos seguráveis.

Contudo, algumas catástrofes no mundo ocidental, e mais concretamente o furacão Katrina, em 2005, revelaram como a exotização, assente em critérios raciais, de classe e de gestão biopolítica e geoeconómica das populações, também funciona em pleno em certos locais geohistóricos do centro hegemónico. Esse processo de exotização, isto é, de transformar concidadãos em estranhos, em atores portadores de alteridade e de diferença, muitas vezes acentuado por lógicas de estereotipação, pode recair sobre determinados grupos sociais ou comunidades, durante e após a ocorrência de acontecimentos extremos e desastres. 
Os desastres são ocasiões que revelam de forma clara as dinâmicas sociais das sociedades afetadas (estruturas sociais, redes sociais, desigualdades, capacidade de resistência) e a qualidade dos serviços estatais, sua organização e lógica de funcionamento. Permitem, também, testar a força dos laços que nos unem, a todos nós, como seres humanos e como cidadãos de diferentes países, colocando dilemas morais, políticos e práticos complexos e, quiçá, irresolúveis. Mas poderão também potenciar o pensar e a concretização de alternativas na construção de um mundo mais justo e igual.

\section{O que dizem ou podem dizer as vítimas e os afetados?}

No seu importante livro Red Tape, Akhil Gupta apresenta estimativas de que há, por ano, na Índia, um excesso de mortes de dois milhões de pessoas devido à pobreza. Para Gupta, o argumento de Amartya Sen (1999) de que o sistema de checks and balances tem sido eficaz nos surtos de fome, de seca ou nos desastres naturais, não se comprova para as mortes ocasionadas pela pobreza na Índia. A pobreza não mobiliza o Estado e os recursos privados neste país (Gupta, 2012, p. 5). As vítimas da pobreza morrem devido a uma violência estrutural e silenciosa exercida sobre elas pelas instituições públicas e privadas.

E, prossegue Akhil Gupta, a situação seria diferente se fossem vítimas de uma catástrofe ou de um desastre, pois imediatamente os mesmos seriam tratados politicamente como uma crise, que originaria uma intervenção massiva do Estado e das instâncias internacionais (Gupta, 2012, p. 4). Embora considere que a pobreza não deve ser teorizada como uma emergência, Gupta reafirma várias vezes este argumento central, contrapondo a visibilidade das vítimas dos desastres à invisibilidade e ao silêncio das vítimas da fome. 
Este argumento de Gupta pode ser falacioso, porque estabelece gradações morais baseadas no número dos afetados ou na projeção mediática. Quantas mortes são equivalentes a quê? E, mais ainda, nas grandes catástrofes, como no terramoto do Haiti, ou no tsunami do Oceano Índico, ou nas grandes inundações na Índia ou no Bangladesh, são os pobres, e entre eles, as mulheres, as pessoas mais afetadas, tanto em mortes como em feridos. O próprio Akhil Gupta (Gupta, 2012, p. 21) reconhece que os eventos catastróficos revelam as iniquidades sociais presentes nas sociedades afetadas, projetando uma realidade que é conhecida apenas pelos pobres no seu dia-a-dia, que vivem num estado de emergência permanente devido às suas características sociais (Giroux, 2006a; 2006b, p. 181).

Uma política emancipadora, baseada na condição de vítima ou de afetado, não se pode ater ao número de pessoas atingidas, mas sim à justiça, aos direitos, à dignidade e à qualidade de vida. Que fios podem ligar os cidadãos e as cidadãs nessa comunhão como simples objetos dos seus Estados? Um cosmopolitismo baseado em singularidades universais?

Uma resposta pode ser encontrada na política da piedade proposta por Luc Boltanski (2000). Este autor define três tópicos do sofrimento: o da denúncia (associado à indignação), o do sentimento (associado à emotividade) e o da estética, propondo que se abandone a versão negativa da compaixão. A política da piedade permite, segundo Luc Boltanski, reconstituir a sua dimensão especificamente política, controversa e até conflictual, numa lógica democrática e de cidadania (Boltanski, 2000; 1999). A proposta de Boltanski resulta numa questão essencial: como pode o sofrimento à distância ser representado e adquirir uma conotação política, que permita a ação, a revolta e a solidariedade?

A questão central é a seleção das vítimas que interessam (por exemplo, quem se lembra que, em 1970, nos ciclones e cheias que atingiram o Bangladesh, morreram entre 300 a 500 mil pessoas?), pois uma política 
da piedade depara-se, e a linguagem é crua e cruel, com um excesso de vítimas, tanto no aspecto material como da sua representação nos meios de comunicação social.

A relegitimação da ação humanitária e a sua repolitização passam pela capacidade dos cidadãos comuns de apreenderem os acontecimentos políticos, e que os sintam no dia-a-dia das suas vidas, nos seus mundos de vida, que os experimentem como dilemas interpelantes pessoais e coletivos, transformando a indignação e a emoção perante o sofrimento de outros numa ação coletiva, de movimentos sociais distintos dos partidos políticos e do Estado.

As catástrofes revelam a nudez política das pessoas, em que os poderes políticos separam os seres políticos (cidadãos) da vida nua (corpos). E, tanto, no Norte como no Sul, não esquecendo séculos de opressão e de dominação coloniais e neocoloniais, todos os cidadãos integrados em Estados e/ou nações podem descobrir a fraqueza do Estado como um terapeuta global imaginário dos seus cidadãos (Sloterdijk, 2006, p. 266).

Se, para Foucault, o racismo é a tanatopolítica da biopolítica (Foucault, 1997, p. 221), para Agamben (1999) a fragmentação do domínio biológico, da vida, é uma fronteira móvel, que se estende à diferença entre a vida animal e a vida orgânica, o humano e o inumano, a vida consciente e a vida vegetativa (Snoek, 2010). ${ }^{8}$

O meu argumento, seguindo esta linha de pensamento, é que as catástrofes e os desastres trazem esta linha divisória para o interior dos Estados. A linha divisória poderá ser estabelecida por critérios raciais, mas também por critérios etários, geográficos, de classe e de diferença sexual.

A necessidade de ir para além da biopolítica e das suas formulações originais avançadas por Michel Foucault (2004), fica patente na reflexão

\footnotetext{
${ }^{8}$ Ver o excelente artigo de Anke Snoek (2010) sobre as relações entre as filosofias de Giorgio Agamben e de Michel Foucault.
} 
suscitada por Akhil Gupta. Para Gupta, a violência e a violência estrutural estão subteorizadas no conceito de biopoder (Gupta, 2012, p. 16). E isto porque a pobreza extrema é uma forma direta e culpável de matar, e não só de deixar morrer ou de se estar exposto à morte. ${ }^{9}$ As mortes devido à pobreza são consequência de uma tanatopolítica, que não se baseia no racismo, mas sim nos recursos económicos (Gupta, 2012, p. 6).

A violência estrutural da pobreza oculta-se na biopolítica, em que os políticos e os funcionários do Estado, das ONGs e das instituições internacionais, se comprazem a analisar quantas pessoas, como grandes números, passaram a linha da pobreza, quantas receberam apoio, quantas estão inseridas nos programas sociais, entre outras estatísticas de gestão dos pobres (Gupta, 2013, p. 687). E, contra as asserções de Giorgio Agamben, Akhil Gupta demonstra que, na Índia, os pobres são mortos apesar da sua inclusão em projetos de soberania nacional e da sua centralidade na política democrática e na legitimação do Estado (Gupta, 2012, p 6). O que caracteriza o Estado na Índia quanto aos pobres é a produção social da indiferença, associada à indiferença quanto à arbitrariedade dos resultados da sua atuação.

Aqui, cabe fazer uma referência, pela pertinência dos conceitos que propõe, e por revelar a insuficiência teórica de Foucault e de Agamben numa era de extremos diretamente associados às várias configurações do neoliberalismo, às propostas de Achile Mbembe (2003). Mbembe afirma que a expressão última de soberania reside, tal como para Foucault, no poder e na capacidade de ditar quem pode viver e quem tem que morrer (Mbembe, 2003, p.11). Achille Mbembe distancia-se claramente das definições de soberania da ciência política e das relações internacionais, não a circunscrevendo às fronteiras de um Estado-nação, às institui-

$\overline{{ }^{9} \text { Relembre-se que, }}$ para Michel Foucault, o biopoder baseia-se no princípio à faire vivre et à laisser mourrir, em contraponto com o lema faire mourrir et laisser vivre do poder soberano (1997: 220). 
Sociologias, Porto Alegre, ano 18, no 43, set/dez 2016, p. 58-86

ções estatais ou a redes ou instituições supranacionais (Mbembe, 2003, p.11, nota 1). O autor interessa-se pelas configurações de soberania cujo projeto central não é a luta pela autonomia, mas sim a instrumentalização generalizada da existência humana e a destruição material de corpos e de populações humanas (2003, p.14). ${ }^{10}$

Achille Mbembe identifica as topografias reprimidas da crueldade (onde cita, entre outras, a plantação e a colónia). Os conceitos de necropolítica e de necropoder, segundo o autor, revelam que as linhas entre resistência e suicídio, sacrifício e redenção, martírio e liberdade ficam esbatidas (Mbembe, 2003, p. 40).

Abre-se, aqui, uma possibilidade de analisar o sofrimento, a redenção, a mobilização, para além das abordagens convencionais do trauma, para a construção de uma política radical de alteridade, não baseada na vitimização passiva, mas na irrupção de alternativas identitárias e políticas, na desestabilização dos quadros comuns adquiridos e das políticas integradoras e securitárias. ${ }^{11}$

A minha reflexão passa, também, pelo diálogo crítico com as propostas de Talal Asad e de Judith Butler. Talal Asad sugere que uma análise assente na dor e na ação abre novas formas de pensar a ação incorporada, para além da abordagem tradicional que toma a dor e a ação como meras expressões holísticas de identidade ou como respostas a oportunidades que se apresentam nas situações vividas.

\footnotetext{
${ }^{10}$ Ver o importante ensaio de Çağatan Topal (2011) sobre os imigrantes turcos na Alemanha. Subhabrata Bobby Banerjee (2006) propõe, na esteira de Mbembe, o conceito de necrocapitalismo, apresentando no seu artigo uma discussão convincente de exemplos dessa vertente do neoliberalismo.

${ }^{11}$ Para uma crítica da Teoria do Ator-Rede e uma proposta sobre o papel das vítimas nas ciências sociais e na sociologia, ver Mendes (2010). lain Wilkinson (2005) apresenta uma proposta interessante de uma sociologia do sofrimento, para além dos objetivos e dos quadros conceptuais da sociologia do risco.
} 
Asad afirma que há formas de experiência em que nos ligamos ao mundo através dos nossos corpos e que implicam um desejo de se deixar ser pessoalmente controlado pelo mundo de determinadas maneiras (Asad, 2003, p. 73). Talal Asad desenvolverá uma reflexão magistral sobre o corpo e a relação deste com a democracia e a cristandade, o mito do corpo violento na religião islâmica e o papel do corpo nas revoltas, em escritos posteriores $(2012 ; 2011 ; 2007)$.

Refletindo sobre o impacto do 11 de Setembro e a necessidade de reinventar uma ética não-violenta que se apresente como uma alternativa à governamentalidade hegemónica, Judith Butler propõe os conceitos de perda, e da mágoa associada a essa perda, e de vulnerabilidade como fundadores da reimaginação da possibilidade de comunidade (Butler, 2004, p. 20-21). A perda fornece um sentimento de comunidade política complexa, pois invoca os laços relacionais que têm implicações para uma teorização da dependência fundamental e da responsabilidade ética. Contra as definições identitárias de uma ontologia liberal, Judith Butler sugere que devemos incorporar nas nossas análises os efeitos contraditórios, dilacerantes da paixão, da mágoa, da dor e da raiva. Para Butler: $A$ paixão, e a dor e a raiva, todas dilaceram-nos de nós próprios, ligam-nos a outros, transportam-nos, desfazem-nos, implica-nos em vidas que não são as nossas, irreversivelmente, se não fatalmente (Butler, 2004, p. 25).

Tal passa por uma teorização do corpo como materialidade implicadora de mortalidade, de vulnerabilidade e de ação. O corpo, constituído como um fenómeno social na esfera pública, é e não é meu. E é a vulnerabilidade de um corpo singular, de vários corpos, de grupos e de comunidades que devem ser reconhecidos, para que a atenção que lhes é dispensada seja potenciadora de um encontro ético. A vulnerabilidade depende das regras existentes do reconhecimento social (Butler, 2004, p. 43). 
No seu livro mais recente de diálogos com Athena Athanasiou, Judith Butler (2013) explicita melhor as estratégias de performatividade que podem combater a despossessão e as políticas neoliberais deliberadas de produção de pessoas e de grupos descartáveis. Tal passa por uma recorporealização do humanismo, e dá como exemplo as frases finais de Frantz Fanon no seu livro Peau Noire, Masques Blancs (Fanon, 1952) que, segundo Judith Butler, abre a hipótese de uma esperança universalizante, sendo, para ela, uma das falas mais insurreccionais de Fanon.

A performatividade pode permitir o direito a aparecer, a estar, isto é, a performatividade nomeia o exercício não autorizado de direito à existência, que propele o precário para o interior da vida política (Butler; Athanasiou, 2013, p. 101). A vitimização, para Butler, tem que passar sempre da dimensão moral para um nível político e socioeconómico, para uma lógica de resistência, para além dos danos ou do trauma (idem, 2013, p. 111).

O reconhecimento pode derivar da práxis das pequenas percepções, como bem mostra May Joseph (2011). Partindo de uma discussão das propostas de Jacques Rancière, em O Destino das Imagens (2011), a autora debruça-se sobre o trabalho performativo da artista finlandesa Pia Lindman nas ruas e nos espaços públicos de Nova lorque, com a performance New York Times, elaborada a partir dos acontecimentos de 11 de Setembro de 2001. Pia Lindman construiu a sua performance a partir de notícias de luto e de dor recolhidas no jornal New York Times. Esta práxis pública apresenta-se como uma crítica do luto e da dor como incapacitações. O que Lindman apresenta é uma forma de fazer em dor (doing grief), em vez de estar em dor (being in grief) (Joseph, 2011, p. 347). É uma práxis que modula as emoções e os sentimentos, para além da simples representação ou da iconicidade da dor e do sofrimento.

Judith Butler discute, por seu lado, o exemplo da artista guatemalteca Regina José Galindo que, para protestar contra a decisão do Supremo 
Tribunal de Justiça da Guatemala de aceitar a candidatura a presidente da república do antigo membro da junta militar, Efraín Ríos Montt, encenou uma performance em 2003 intitulada, Quién puede borrar las huellas? (Butler; Athenasiou, 2013, p. 169-172).

A performance consistia na artista, com um vestido negro e com uma bacia branca cheia de sangue, imergir os pés na bacia e caminhar, do edifício do Supremo Tribunal ao edifício presidencial do Palácio Nacional, deixando pegadas de sangue ao longo do seu trajeto. Para Butler, esta performance,

[...] através destes trabalhos, o corpo sofre, cai, é manietado e dominado por forças externas, mas o corpo do performer também persiste, sobrevive, apresentando e representando uma história social, memorializando as formas de sofrimento e de perda contra o logro do esquecimento (Butler; Athenasiou, 2013, p. 172).

O papel da arte na reflexão sobre a práxis dos pequenos momentos nas catástrofes, pode, ainda, ser apreendida a partir do trabalho de Ai Weiwei. Na sua exposição intitulada So Sorry, no Haus der Kunst, em Munique, no ano de 2009, Weiwei apresentou, na fachada de entrada do museu, a instalação Remembering. A frase inscrita nas mochilas escolares que figuravam no exterior dizia em caracteres chineses: Ela viveu de forma feliz por sete anos neste mundo. Esta frase foi dita por uma das mães de uma das crianças mortas no terramoto de Sichuan, de Maio de 2008. Muitas das vítimas foram crianças que estavam nas escolas. ${ }^{12}$ Segundo Ai Weiwei:

\footnotetext{
${ }^{12} \mathrm{Ai}$ WeiWei tomou a iniciativa de recolher todos os nomes das crianças que morreram no terramoto soterradas nas escolas, um dado considerado secreto pelas autoridades, e recolheu cerca de 5.700 nomes. WeiWei publicou a lista dos nomes no seu blogue, tendo o mesmo sido posteriormente encerrado pelas autoridades. Um excelente documentário sobre Weiwei foi realizado por Alison Klayman (2012).
} 
Sociologias, Porto Alegre, ano 18, no 43, set/dez 2016, p. 58-86

A ideia de utilizar mochilas partiu da minha visita a Sichuan depois do terramoto. Durante o terramoto, muitas escolas colapsaram. Milhares de estudantes perderam as suas vidas, e podia-se ver pastas e material de estudo por todo o lado. Então, apercebes-te que a vida individual, a mídia e as vidas dos estudantes estão a servir objetivos muito distintos. As vidas dos estudantes desapareceram no interior da propaganda do Estado e, muito em breve, toda a gente esquecerá tudo. Se quiser, cada uma das 9.000 mochilas na frente do museu representa a perda da vida de uma criança (Lambert, 2009).

E, afirma ainda Weiwei:

Fazemos o luto, só porque a morte faz parte da vida, porque os que morreram devido ao terramoto fazem parte de nós. Contudo, os mortos foram-se. Só quando os que estão vivos continuam a viver com dignidade, podem os que partiram descansar com dignidade (Lambert, 2009).

Esta proposta, e a exposição significativa do sofrimento, que pode criar alternativas aos discursos e às práticas dominantes que invisibilizam os mais vulneráveis, remete para a forma como a sociologia pode, numa abordagem às catástrofes e aos desastres, desconstruir e trabalhar os mediadores da memória e contribuir para uma epistemologia emancipadora e indutora de dignidade. Nesta perspetiva, contar-se-ia sempre, entre os mediadores da memória, com pessoas diretamente afetadas, ou por seus representantes democraticamente escolhidos.

A dimensão pública das identidades pessoais, grupais e coletivas assenta na codificação, institucionalização e simbolização dos acontecimentos que marcam de forma indelével os indivíduos e as comunidades. As memórias sociais, para serem eficazes, têm que ser celebradas e comemoradas. Um papel crucial é desempenhado pelos mediadores e empresários da memória que, de uma forma contínua, tentam reiterar as certezas e as raízes, fixar e cristalizar tradições, contra o efeito desafiador do improvável e do imprevisto. 
Pelo seu próprio trabalho, os mediadores da identidade tentam impedir o pensar de alternativas, fechando o campo celebratório. Mas, para além das memórias e das identidades oficiais, luta-se por identidades performativas, ativadas e consolidadas no quotidiano, em múltiplas práticas de desobjectificação e de resistência.

Embora as relações de poder e de biopoder estejam sempre presentes e embebidas nos processos de simbolização e de ritualização, deve ser dada uma atenção especial à capacidade de resistir, aos discursos e às práticas contra-hegemónicos que são propalados por memórias individuais e coletivas subterrâneas, que trabalham, modificam e recusam as memórias públicas e oficiais.

A dignidade é a possibilidade de viver e expressar as múltiplas pertenças de cada indivíduo ou grupo. Mas, devemos fazer algumas perguntas importantes. A quem e a quê pertencemos (Nathan, 2007)? O quê, nos permitem estas pertenças fazer, e o quê, restringem ou proíbem? Os espaços democráticos convencionais permitem essa expressão das pertenças múltiplas? Que pertenças são mobilizadas para oprimir ou suprimir os outros?

\section{Conclusão}

Neste artigo, abordei a forma como os acontecimentos extremos e as catástrofes revelam a lógica de funcionamento e de atuação do capitalismo, e como, no limite, os Estados são o garante último de apoio e de reconstituição dos laços sociais e das comunidades após a ocorrência de um desastre.

Contrariamente a muitas das análises académicas do capitalismo, este não apresenta uma forma ou força únicas, mas adapta-se às circunstâncias que encontra, desde que o seu princípio básico de acumulação infinita de capital não seja colocado em causa. Por outro lado, o capitalismo 
não é homoeficiente, e pode conviver com as formas mais extremadas de estatismo ou as políticas neoliberais mais desenfreadas. Certo é que, sem a existência dos Estados, e a prerrogativa de autoridade e de poder político, será difícil ao capitalismo reproduzir-se.

A catástrofe e o desastre revelam a verdadeira lógica de funcionamento dos Estados e da sua articulação com o sistema histórico capitalista. Em última instância, todos os cidadãos e cidadãs podem ver a sua relação fictícia com a entidade estatal e o seu estatuto outorgado de cidadania colocados em questão após uma catástrofe ou um desastre. As catástrofes revelam a nudez política das pessoas, em que os poderes políticos separam os seres políticos (cidadãos) da vida nua (corpos).

Contrariamente à biopolítica de Foucault, a tanatopolítica numa catástrofe pode não assentar no racismo, mas em qualquer critério de classificação, como o lugar de residência, a idade, o sexo, a origem geográfica, ou outro construído de forma arbitrária. E a pergunta central a fazer será: que podem os corpos em presença, pela ação coletiva e pela resistência, e de forma performativa, fazer para desconstruírem a lógica mercantil e obrigarem o poder político à restituição da dignidade, ao reconhecimento das pertenças?

O essencial é analisar o papel das vítimas e dos afetados, das suas comunidades e associações, na construção de contranarrativas, como reveladoras da crueldade do neoliberalismo, e como potenciadoras de uma globalização contra-hegemónica, não baseada na comunhão do sofrimento ou no trauma, mas na convergência de corpos e nas performances que sejam moduladoras de sentimentos politicamente significativos.

O objetivo é partir de experiências fragmentadas, quase inaudíveis, de murmúrios silenciados, de discursos e práticas que arriscam, e construir humildemente uma ciência social que interessa, está atenta à ecologia dos saberes e contribui para um mundo alternativo. 
José Manuel Mendes é Doutor em Sociologia, professor auxiliar com Agregação da Faculdade de Economia da Universidade de Coimbra, investigador sénior do Centro de Estudos Sociais da Universidade de Coimbra. $\$ jomendes@fe.uc.pt

\section{Referências}

1. AGAMBEN, G. The Remnants of Auschwitz: The Witness and the Archive. London: Zone Books, 1999.

2. ARRIGHI, G. The Long Twentieh Century. London: Verso, 2010.

3. ASAD, T. Formations of the Secular. Christianity, Islam, Modernity. Stanford: Stanford University Press, 2003.

4. ASAD, T. On Suicide Bombing. New York: Columbia University Press, 2007.

5. ASAD, T. Thinking About the Secular Body, Pain and Liberal Politics. Cultural Anthropology, v. 26, n. 4, p. 657-675, nov. 2011.

6. ASAD, T. Fear and the Ruptured State: Reflections on Egypt After Mubarak. Social Research, v. 79, n. 2, p. 271-298, 2012.

7. BANERJEE, S.B. Live and Let Die: Colonial Sovereignties and the Death Worlds of Necrocapitalism. Borderlands, v. 5, n. 1, 2006. Disponível em: < http:// www.borderlands.net.au/vol5no1_2006/banerjee_live.htm>. Acesso em: 28 dez. 2015.

8. BANKOFF, G. The Historical Geography of Disaster: 'Vulnerabilility' and 'Local Knowledge' in Western Discourse. In: BANKOFF, G.; FARKS, G.; HILHORST, D.(eds.). Mapping vulnerability. Disasters, Development and People. London: Earthscan, 2004. p. 25-36.

9. BANKOFF, G. Comparing Vulnerabilities: Toward Charting an Historical Trajectory of Disasters. Historical Social Research, v. 32, n. 3, p. 103-114, 2007.

10. BARBER, B. Jihad vs McWorld. New York: Ballantine Books, 1996.

11. BECK, U. The Risk Society. Towards a New Modernity. London: Sage, 1992.

12. BECK, U. World at Risk. Cambridge: Polity Press, 2008.

13. BOLTANSKI, L. La souffrance à distance. Paris: Metailié, 1999

14. BOLTANSKI, L. The Legitimacy of Humanitarian Actions and Their Media Representation: The Case of France. Ethical Perspectives, v. 7, n. 1, p. 3-15, abr. 2000. 
Sociologias, Porto Alegre, ano 18, o 43, set/dez 2016, p. 58-86

15. BOUGEN, P. Catastrophe Risk. Economy and Society, v. 32, n. 2, p. 253-274, mai. 2003.

16. BUTLER, J. Precarious Life. The Powers of Mourning and Violence. London: Verso, 2004.

17. BUTLER, J.; ATHANASIOU, A. Dispossession: the Performative in the Political. London: Polity, 2013.

18. CALLON, M.; LASCOUMES, P.; BARTHE, Y. Agir dans un monde incertain. Essai sur la démocratie technique. Paris: Le Seuil, 2001.

19. CHAKRABARTY, D. Provincializing Europe. Postcolonial Thought and Historical Difference. Princeton, NJ: Princeton University Press, 2008.

20. COLLIER, S. Enacting Catastrophe: Preparedness, Insurance, Budgetary Rationalization. Economy and Society, v. 37, n. 2, p. 224-250, mai. 2008.

21. DELEUZE, G.; GUATTARI, F. Mil planaltos. Capitalismo e esquizofrenia 2. Lisboa: Assírio e Alvim, 2008.

22. DERLEUGIAN, G. (Ed.). Does Capitalism Have a Future? New York: Oxford University Press, 2013.

23. EWALD, F. L' état providence. Paris: Grasset, 1986.

24. EWALD, F. The Return of Descartes' Malicious Demon: An Outline of a Philosophy of Precaution. In: BAKER, T.; SIMON, J. Embracing Risk. The Changing Culture of Insurance and Responsibility. Chicago: The University of Chicago Press, 2002, p. 273-301.

25. FANON, F. Peau noir, masques blancs. Paris: Seuil, 1952.

26. FOUCAULT, M. Il faut défendre la societé. Cours au Collège de France, 1976. Paris: Hautes Études, Gallimard, Seuil, 1997.

27. FOUCAULT, M. La naissance de la biopolitique. Cours au Collège de France, 1978-1979. Paris: Hautes Études, Gallimard, Seuil, 2004.

28. GIROUX, H. Stormy Weather. Katrina and the Politics of Disposability. Boulder, CO: Paradigm Publishers, 2006a.

29. GIROUX, H. Reading Hurricane Katrina: Race, Class, and the Biopolitics of Disposability. College Literature, v. 33, n. 3, p.171-196, $2006 \mathrm{~b}$.

30. GUPTA, A. Red Tape. Bureaucracy, Structural Violence and Poverty in India. Durham, NC: Duke University Press, 2012.

31. GUPTA, A. Structural Violence and Politics, Economy and Society, v. 42, n. 4, p. 686-692, nov. 2013. 
32. HIBOU, B. La bureaucratisation du monde à I' ère néoliberale. Paris: La Découverte, 2012.

33. JASANOFF, S. (Ed.). Learning from Disaster. Risk management after Bhopal. Philadelphia, PA: University of Pennsylvania Press, 1994.

34. JASANOFF, S. Technologies of Humility: Citizen Participation in Governing Science. Minerva, v. 41, p. 223-244, 2003.

35. JASANOFF, S. Designs on Nature. Science and Democracy in Europe and the United States. Princeton, NJ: Princeton University Press, 2005.

36. JOSEPH, M. Fascia and the grimace of catastrophe. In: SMITH, P. C.; WILLSE, C. (eds.). Beyond Biopolitics. Essays in the Governance of Life and Death. Durham, NC: Duke University Press, 2011, p. 332-350.

37. KLAYMAN, A. Ai Weiwei. Never Sorry. London: Artificial Eye, 2012.

38. KLEIN, N. The Shock Doctrine. The Rise of Disaster Capitalism. London: Allen Lane, 2007.

39. KROLL-SMITH, S. Cidadania, Estado e vulnerabilidade: um estudo comparado sobre a recuperação de catástrofes. In: MENDES, J.M.; ARAÚJO, P. (orgs.). Os lugares (im)possíveis da cidadania. Estado e risco num mundo globalizado. Coimbra: Edições Almedina/CES, 2012, p. 255-288.

40. LAMBERT, U.G. Ai Weiwei in Munich, Premier Art Scene. Germany, 2009. Disponível em: <http://premierartscene.com/magazine/ai-weiwei-in-munich/>. Acesso em: 29 dez. 2015.

41. MBEMBE, A. Necropolitics. Public Culture. v.15, n. 1, p. 11-40, 2003.

42. MENDES, J.M. Pessoas sem voz, redes indizíveis e grupos descartáveis: os limites da Teoria do Actor-Rede. Análise Social, v. XLV, n. 196, p. 447-465, 2010.

43. MITCHELL, T. Rule of Experts. Egypt, Techno-Politics, Modernity. Berkeley: University of California Press, 2002.

44. MITCHELL, T. Carbon Democracy. Political Power in the Age of Oil. London: Verso, 2011.

45. MIROWSKI, P. Never Let a Serious Crisis Go To Waste. How Neoliberalism Survived the Financial Meltdown. London: Verso, 2013.

46. NANCY, J-L. Les catastrophes en équivalence (Après Fukushima). Paris: Éditions Galilée, 2012.

47. NATHAN, T. À qui j'appartiens? Écrits sur la psychothérapie, sur la guerre et sur la paix. Paris: Editions Le Seuil/Les Empêcheurs de penser en rond, 2007. 
Sociologias, Porto Alegre, ano 18, no 43, set/dez 2016, p. 58-86

48. NKRUMAH, K. Neo-colonialism. The Last Stage of Imperialism. London: Thomas Nelson \& Sons, 1965.

49. ONG, A. Neoliberalism as Exception. Mutations in Citizenship and Sovereignty. Durham, NC: Duke University Press, 2009.

50. ONG, A. Powers of Sovereignty: State, People, Wealth, Life. Focaal-Journal of Global and Historical Anthropology, n. 64, p. 24-35, 2012.

51. POWER, M. Organized Uncertainty. Designing a World of Risk Management. Oxford: Oxford University Press, 2007.

52. RANCIÈRE, J. O destino das imagens. Lisboa: Orfeu Negro, 2011.

53. ROSE, N. Governing "Advanced" Liberal Democracies. In: BARRY, A.; OSBORNE, T.; ROSE, N. (eds.). Foucault and Political Reason: Liberalism, Neoliberalism, and Rationalities of Government. Chicago: University of Chicago Press, 1996, p. 37-64.

54. SANTOS, B.de S. O Estado e os modos de produção de poder social. In: Pela mão de Alice. O social e o político na pós-modernidade. Porto: Edições Afrontamento, p. 103-118, 1994.

55. SANTOS, B.de S. Towards a New Common Sense. Law, Science and Politics in the Paradigmatic Transition. New York: Routledge, 1995.

56. SANTOS, B.de S. Pode o direito ser emancipatório? Revista Crítica de Ciências Sociais, n. 65, p. 3-76, 2003.

57. SANTOS, B.de S. Para além do pensamento abissal: das linhas globais a uma ecologia dos saberes. Revista Crítica de Ciências Sociais, n. 78, p. 3-46, 2007.

58. SANTOS, B.de S. Para uma teoria pós-colonial do risco. Comunicação apresentada no colóquio internacional Risco e o estado num mundo globalizado. Coimbra: Centro de Estudos Sociais, 2009.

59. SEN, A. Development as Freedom. New York: Alfred Knopf, 1999.

60. SLOTERDIJK, P. Le palais de cristal. À I' intérieur du capitalisme planétaire. Paris: Maren Sell Éditeurs, 2006.

61. SMITH, P.C.; WILLSE, C. Beyond Biopolitics. The Governance of Life and Death. In: SMITH, P.C.; WILLSE, C. (eds.). Beyond Biopolitics. Essays in the Governance of Life and Death. Durham, NC: Duke University Press, 2011, p. 1-16.

62. SNOEK, A. Agamben's Foucault: An Overview. Foucault Studies, n. 10, p. 44-67, nov. 2010. 
63. TOPAL, Ç. Necropolitical Surveillance: Immigrants from Turkey in Germany. In: SMITH, P.C.; WILLSE, C. (eds.). Beyond Biopolitics. Essays in the Governance of Life and Death. Durham, NC: Duke University Press, 2011, p. 238-257.

64. VON DAHLEN, S.; VON PETER, G. Natural Catastrophes and Global Reinsurance. BIS Quarterly Review, p. 23-35, dez. 2012.

65. WILKINSON, I. Suffering: A Sociological Introduction. Oxford: Polity Press, 2005.

66. WRIGHT, E.O. Envisioning Real Utopias. London: Verso, 2010.

Recebido:15.01.2016

Aceite: 10.05.2016 